\section{Destructive Temporomandibular Joint Disease: Also Consider Tophaceous Voracious (Hydroxy)Apatite}

\section{To the Editor:}

The article by Reynolds, et al presents a case of destruction of the temporomandibular joint (TMJ) attributed to tophaceous calcium pyrophosphate dihydrate (CPPD) deposition ${ }^{1}$. The authors also review the literature regarding 34 similar cases of chronic tophaceous destructive lesions, many also involving the TMJ and adjacent anatomical sites.

Most previous case reports describing tophaceous crystal-containing destructive masses have relied on morphology and birefringence properties to classify the crystals observed, but have not identified the molecular nature of the crystal by more specific techniques. We wonder if Reynolds, et al have confirmed the identity of the crystals they observed.

We previously described a similar case of tophaceous destruction of the $\mathrm{TMJ}^{2}$. In our case, the mass also eroded into the infratemporal fossa and was associated with hyperparathyroidism. Surprisingly, when the weakly positively birefringent crystals were analyzed by x-ray crystallography and infrared spectroscopy, we found them to be composed of hydroxyapatite, rather than the calcium pyrophosphate dihydrate (CPPD) that we were expecting. In most clinical situations, weakly birefringent crystals with rhomboid or rodlike structures are appropriately identified as CPPD; however, (hydroxy)apatite crystals may also be weakly birefringent. For example, in the original description of Milwaukee shoulder, the hydroxyapatite crystals were weakly birefringent in some cases ${ }^{3}$. Large laminated apatite crystals may also occasionally be birefringent ${ }^{4}$.

We wonder if the case described by Reynolds, et al, like ours and per- haps other similar cases, may be a destructive process caused by apatite, rather than CPPD. Analogous to the destructive nature of Milwaukee shoulder, this may be considered "Milwaukee TMJ," or tophaceous, voracious (hydroxy)apatite.

MARK H. WENER, MD, Divisions of Immunology and Rheumatology, University of Washington, Seattle, Washington 98195, USA.

E-mail: wener@u.washington.edu

\section{REFERENCES}

1. Reynolds JL, Matthew IR, Chalmers A. Tophaceous calcium pyrophosphate dihydrate deposition disease of the temporomandibular joint. J Rheumatol 2008;35:717-21.

2. Grant GA, Wener MH, Yaziji H, et al. Destructive tophaceous calcium hydroxyapatite tumor of the infratemporal fossa. Case report and review of the literature. J Neurosurg 1999;90:148-52.

3. McCarty DJ, Halverson PB, Carrera G, et al: "Milwaukee shoulder" - association of microspheroids containing hydroxyapatite crystals, active collagenase, and neutral protease with rotator cuff defects. I. Clinical aspects. Arthritis Rheum 1981;24:464-73.

4. Schumacher HR, Rothfuss S, Bertken R, et al. Unusual laminated birefringent arrays of apatite crystals in inflammatory arthritis [abstract]. Arthritis Rheum 1987;30 Suppl:S106.

J Rheumatol 2009;36:2; doi:10.3899/jrheum.080520 